\title{
Experience of living donor liver transplantation for hepatocellular carcinoma in the University of Hong Kong Hospital
}

\author{
Janice Hoi Man Mok', Ka Wing Ma², Kenneth Siu Ho Chok ${ }^{2}$ \\ 1 Li Ka Shing Faculty of Medicine, The University of Hong Kong, Hong Kong, China. \\ ${ }^{2}$ Department of Surgery, The University of Hong Kong, Hong Kong, China.
}

Correspondence to: Dr. Kenneth Siu Ho Chok, Department of Surgery, The University of Hong Kong, 102 Pok Fu Lam Road, Hong Kong, China. E-mail: kennethchok@gmail.com

\begin{abstract}
How to cite this article: Mok JHM, Ma KW, Chok KSH. Experience of living donor liver transplantation for hepatocellular carcinoma in the University of Hong Kong Hospital. Hepatoma Res 2022;8:6. https://dx.doi.org/10.20517/2394-5079.2021.125
\end{abstract}

Received: 19 Sep 2021 First Decision: 16 Nov 2021 Revised: 6 Dec 2021 Accepted: 30 Dec 2021 Published: 8 Feb 2022

Academic Editor: Nobuhisa Akamatsu Copy Editor: Yue-Yue Zhang Production Editor: Yue-Yue Zhang

\begin{abstract}
Aim: To describe the current practise of living donor liver transplantation (LDLT) for hepatocellular carcinoma (HCC), including the patient selection criteria, surgical techniques, management of small-for-size syndrome, postoperative complications, and the results of our units, in the Liver Transplant Centre of Queen Mary Hospital, Hong Kong, one of the high-volume centres for LDLT in Asia.

Methods: Our centre practises careful selection for HCC patients using the University of California, San Francisco (UCSF) criteria, supplemented by alpha-fetoprotein level and the model for end-stage liver disease score. Slight flexibility is offered to enthusiastic donors and recipients in LDLT while balancing the risks and benefits. We pioneered in using the extended right lobe graft and the novel hepatic venoplasty technique, which lessen the risk of hyperperfusion and small-for-size syndrome with improved overall recipient survival. Data were collected prospectively and presented as the mean values and ranges, or the number of patients in proportion of total patient population.
\end{abstract}

Results: Of our patients, $74.9 \%$ met the UCSF criteria, and $64.5 \%$ met the Milan criteria. A 5 -year overall and disease-free survival rate of $78.9 \%$ and $76.3 \%$ were achieved. 
Conclusion: LDLT is an ideal treatment for HCC in Hong Kong with regard to the critical organ shortage and high demand for transplantation. The current surgical techniques and post-transplant surveillance contribute to the positive outcome.

Keywords: Living donor liver transplantation, hepatocellular carcinoma, high volume centre, LDLT, HCC

\section{INTRODUCTION}

Hepatocellular carcinoma (HCC) is the third most common fatal cancer in Hong Kong with a crude death rate of 21.9 per 100,000 population. Liver transplantation is often regarded as the best curative treatment for HCC with a 5 -year overall survival rate of $89.9 \%{ }^{[1]}$. The scarcity of cadaveric liver donation in Asia due to cultural and religious beliefs has undermined the possibility of deceased donor liver transplantation $(\mathrm{DDLT})^{[2]}$. The deceased graft liver donation rate in Hong Kong is as low as 3.07 per 1,000,000 population, compared to 25.61 in the United States ${ }^{[3]}$. Since the first report of successful adult-to-adult living donor liver transplantation (LDLT) using extended right lobe graft from our centre in $1997^{[4]}$, LDLT gained popularity in Hong Kong as well as in other Asian countries. It serves as the last hope of cure for cirrhotic HCC patients amid the shortage of deceased donors. By the end of 2018, our centre completed over 1400 liver transplants with overall 1-year, 3-year, and 5 -year survival rates of $93.0 \%, 88.1 \%$, and $85.7 \%$, respectively ${ }^{[5]}$. Among all the transplant cases, 231 LDLT for HCC patients were performed.

Studies demonstrated improved mortality and other long-term post-transplant outcomes from high volume centres $^{[6,7]}$. In 2019, South Korea topped the world with 22.87 LDLT per 1,000,000 population, followed by Taiwan, the People's Republic of China, and Japan ${ }^{[3]}$. Hong Kong ranked 6th in the world in terms of LDLT rates, with 2.67 LDLT per 1,000,000 population. As experience accumulated, there were continuous modifications of patient management. All these were translated into better treatment outcomes. The Liver Transplant Centre of Queen Mary Hospital, Hong Kong is one of the high-volume centres for LDLT in Asia that adopted the University of California, San Francisco (UCSF) criteria.

In this article, we will discuss the current practise of LDLT, including patient selection criteria, surgical techniques, management of small-for-size syndrome (SFSS) and postoperative complications, oncological outcomes in HCC patients at the high-volume centres, and results of our units.

\section{METHODS}

\section{Surgical techniques}

Extended right lobe graft and venous outflow regulation

Our centre established the use of the extended right lobe graft in LDLT since $1997^{[4]}$. The graft contains the whole right lobe with segments V, VI, VII, and VIII, the middle hepatic vein, and right inferior hepatic veins of size $>5 \mathrm{~mm}^{[8]}$. The procedure of extended right lobectomy is performed through bilateral subcostal incisions with an upward median extension to the xiphoid. Intraoperative ultrasonography is taken to determine configuration of the right, middle, and left hepatic veins. The correct transaction plane displays the longitudinal section of the middle hepatic vein together with the inferior vena cava. Hilar dissection is then performed to free the hepatic artery and right portal vein ${ }^{[9-18]}$.

\section{Hepatic venoplasty}

The maintenance of venous outflow is important in healthy functioning of the liver. In contrast to whole liver graft from a deceased donor, hemi-graft used in LDLT carries a shorter hepatic vein caliber, that implies more difficult reconstruction, higher risk of angulation and poorer venous outflow ${ }^{[9]}$. While 
inclusion of the middle hepatic vein in extended right lobe graft improves transplant outcome, the reconstruction process of the inferior vena cava anastomosis is technically demanding. Precise adjustment of the length, orientation, and diameter of the anastomosis is required.

In 2000, our centre pioneered a hepatic venoplasty technique that minimizes the above technical difficulties $^{[10]}$. Following donor hepatectomy, the inflow and outflow vessels of the graft are trimmed at the back table. A 5-mm transverse incision is made to create a depression between the middle and right hepatic veins. Adjacent walls of the vessels are then sutured using two 6-0 prolene stitches placed $1 \mathrm{~cm}$ apart. The combined outflow lumen is enlarged to form a single triangular cuff, with the right hepatic vein as the base, and middle hepatic vein as the apex of the triangle. The recipient undergoes total hepatectomy with the inferior vena cava preserved. The modified outflow vessels are then sutured onto a triangular incision on the recipient's inferior vena cava using 5-0 prolene ${ }^{[11]}$.

The novel technique using extended right lobe graft in LDLT is now widely applied in many centres. It eliminates the need for a sufficient length of the hepatic vein calibre for anastomosis, prevents hepatic venous blockage, and reduces outflow resistance ${ }^{[10]}$.

\section{Microvascular anastomosis}

Nowadays, microvascular anastomosis has been adopted as a standard procedure in hepatic artery reconstruction ${ }^{[19]}$. At our center, this part of the transplantation is performed by the team of Plastic and Reconstructive Surgery. The operating microscope, microinstruments and microsutures using 9-0 prolene are applied in the procedure ${ }^{[1]}$.

Hepatic artery segments from the donor and the recipient are clamped, with distal end blood clots removed by heparin saline irrigation. Two stay sutures are then placed at $0^{\circ}$ and $160^{\circ}$ with the subsequent stitches made from the lateral to the central part. Any discrepancy in the whole vessel circumference is carefully adjusted. Upon completion of the anastomosis, the vascular clamps are removed with an instant restoration of arterial blood flow. Doppler ultrasonography is applied to assess the efficacy of the anastomosis and the overall perfusion of the liver graft. Extra stitches may be added in instances of bleeding or separation of the vessel wall ${ }^{[11]}$.

\section{Statistical analysis}

Graft and patient overall and disease-free survival at 1 year, 3 years, and 5 years after transplantation were the primary endpoints, and the secondary endpoints were complication rate. Data were collected prospectively and presented as the mean values and ranges, or the number of patients in proportion of total patient population.

\section{RESULTS}

By May 2020, 231 HCC patients received LDLT at our centre [Table 1]. There were more male than female recipients, at a ratio of 3.62:1. The recipients were predominantly Asian and had a mean age of 56 years (range: $3-73$ ). Of the patients, $76.6 \%$ were tested positive for hepatitis B virus (HBV).

Of our patients, $74.9 \%$ met the UCSF criteria, and $64.5 \%$ met the Milan criteria [Table 2]. The majority of our LDLT recipients had a relatively low AFP level of $22 \mathrm{ug} / \mathrm{L}$. However, there was a wide range (range: 2$117850 \mathrm{ug} / \mathrm{L}$ ). 
Table 1. Demographic data of recipients and donors undergoing living donor liver transplantation for hepatocellular carcinoma in Hong Kong

\begin{tabular}{ll}
\hline Total No. of recipients & 231 \\
Recipient age, years & $56(3-73)$ \\
Recipient sex & $181(78.4 \%)$ \\
Male & $50(21.6 \%)$ \\
Female & \\
Recipient ethnicity & $230(99.6 \%)$ \\
Asian & $1(0.4 \%)$ \\
White & \\
Diagnosis & $174(75.3 \%)$ \\
HBV & $39(16.9 \%)$ \\
HCV & $3(1.3 \%)$ \\
Both HBV and HCV & $202(87.4 \%)$ \\
Cirrhosis & $17(7.4 \%)$ \\
Acute-on-chronic liver failure & $8(3.5 \%)$ \\
Chronic active hepatitis & $2(0.9 \%)$ \\
Primary biliary cirrhosis & $1(0.4 \%)$ \\
Biliary atresia & $1(0.4 \%)$ \\
Chronic active hepatitis with acute flare & $34(18-58)$ \\
Donor age, years & \\
Donor sex & $87(37.7 \%)$ \\
Male & $144(62.3 \%)$ \\
Female &
\end{tabular}

HBV: Hepatitis B virus; HCV: hepatitis C virus.

\section{Table 2. Biological and explant pathological profile in recipients undergoing living donor liver transplantation}

\begin{tabular}{ll}
\hline MELD score & $11.6(6-59)$ \\
Platelet & $68(16-234)$ \\
Creatinine & $80(34-444)$ \\
Total bilirubin & $29(4-775)$ \\
INR & $1.3(0.9-10.0)$ \\
AFP & $22(2-117850)$ \\
Tumour size (cm) & $3.0(0.9-19.5)$ \\
Tumour number & $1(1-20)$ \\
UCSF criteria & \\
$\quad$ Within criteria & $173(74.9 \%)$ \\
$\quad$ Beyond criteria & $57(24.7 \%)$ \\
$\quad$ No viable tumour & $1(0.4 \%)$ \\
Milan criteria & \\
$\quad$ Within criteria & $149(64.5 \%)$ \\
$\quad$ Beyond criteria & $81(35.1 \%)$ \\
$\quad$ No viable tumour & $1(0.4 \%)$ \\
\hline
\end{tabular}

MELD: Model for end-stage liver disease; INR: international normalised ratio; AFP: alpha-fetoprotein; UCSF: University of California, San Francisco criteria.

The standard procedure accounted for $91.8 \%$ of the operations and nearly all of the adult-to-adult transplants [Table 3]. Transplants for pediatric patients or recipients with smaller body size sometimes 
Table 3. Perioperative details of recipients undergoing living donor liver transplantation

\begin{tabular}{ll}
\hline Graft type & \\
$\quad$ Right lobe & $212(91.8 \%)$ \\
$\quad$ Left lobe & $18(7.8 \%)$ \\
$\quad$ Left lateral segment & $1(0.4 \%)$ \\
Graft weight to recipient (HKUESLV) (\%) & $42.8(24.4-76.4)$ \\
Small-for-size-graft (<30\%) & $13(5.6 \%)$ \\
Graft weight to recipient body weight (\%) & $0.82(0.47-1.57)$ \\
Recipient operation time (min) & $705(401-1273)$ \\
Cold ischemic time (min) & $102(39-334)$ \\
Recipient blood loss (mL) & $2500(250-30000)$ \\
Intra-operative blood transfusion (unit) & $4(0-63)$ \\
Recipient without blood transfusion & $76(32.9 \%)$ \\
Duration of hospital stay (days) & $17(7-354)$ \\
Duration of ICU stay (days) & $3(1-283)$ \\
\hline
\end{tabular}

HKUESLV: The University of Hong Kong model for estimated standard liver volume; ICU: intensive care unit.

involve the use of a left lobe graft, which constituted 18 out of 231 cases. The median graft volume to standard liver volume was $42.8 \%$, including 13 cases of small-for-size graft, which were placed under intensive post-transplant surveillance to reduce SFSS-related complications.

Our centre attained a 1-year, 3-year, and 5-year overall survival rate of 96.0\%, 84.7\%, 78.9\%, respectively. The 1-year, 3-year, and 5-year disease-free survival rates were $88.9 \%, 79.8 \%$, and $76.3 \%$, respectively [Table 4]. Significant disease-free and overall survival were demonstrated among transplant recipients within Milan criteria and the UCSF criteria [Figures 1-4]. Of the patients, 18.6\% suffered HCC recurrence. The long-term graft survival rate at 1-year, 3-year, and 5-year follow-up were 93.4\%, $83.0 \%$, and $77.3 \%$, while $9.1 \%$ of patients suffered from graft rejection and were subjected to conservative treatment and reoperations. Of the patients, $26.4 \%$ suffered from Grade III or above, and 5.2\% suffered from Grade IV or above early postoperative complications according to the Clavien-Dindo Classification ${ }^{[20]}$. The most common ones include pleural effusion, intra-abdominal abscess, chest infection, and hepatic artery thrombosis (HAT). Late complications, including biliary stricture, portal vein thrombosis, and stenosis, were recorded. There had been two cases of hospital mortality, relating to acute myocardial infarction and to multiorgan failure from bronchopneumonia and necrotic liver graft.

\section{DISCUSSION}

\section{The experience of LDLT for HCC in Hong Kong}

Hong Kong is one of the endemic regions for HBV infection. Chronic HBV infection is the primary etiology of developing cirrhosis and $\mathrm{HCC}^{[21]}$. A large proportion of our patients tested positive for the virus. In such cases, LDLT is considered the best therapeutic option, given the shorter waiting time, better graft quality, and essentially no cold ischemic time.

\section{Recipient and donor selection}

Patients with HCC were chosen based on the pretransplant radiological tumour staging. Computed tomography (CT) of the abdomen was performed to delineate the tumour size and number. Morphological assessment of HCC based on the Milan criteria (one lesion $\leq 5 \mathrm{~cm}$ or two to three lesions $\leq 3 \mathrm{~cm}$ ) has been the gold standard for patient selection ${ }^{[22]}$. However, the criteria are often considered too restrictive as tumour biology is only partially represented by tumour size and number. Our centre adopted the UCSF 
Table 4. Outcome of living donor liver transplantation for hepatocellular carcinoma patients in Hong Kong

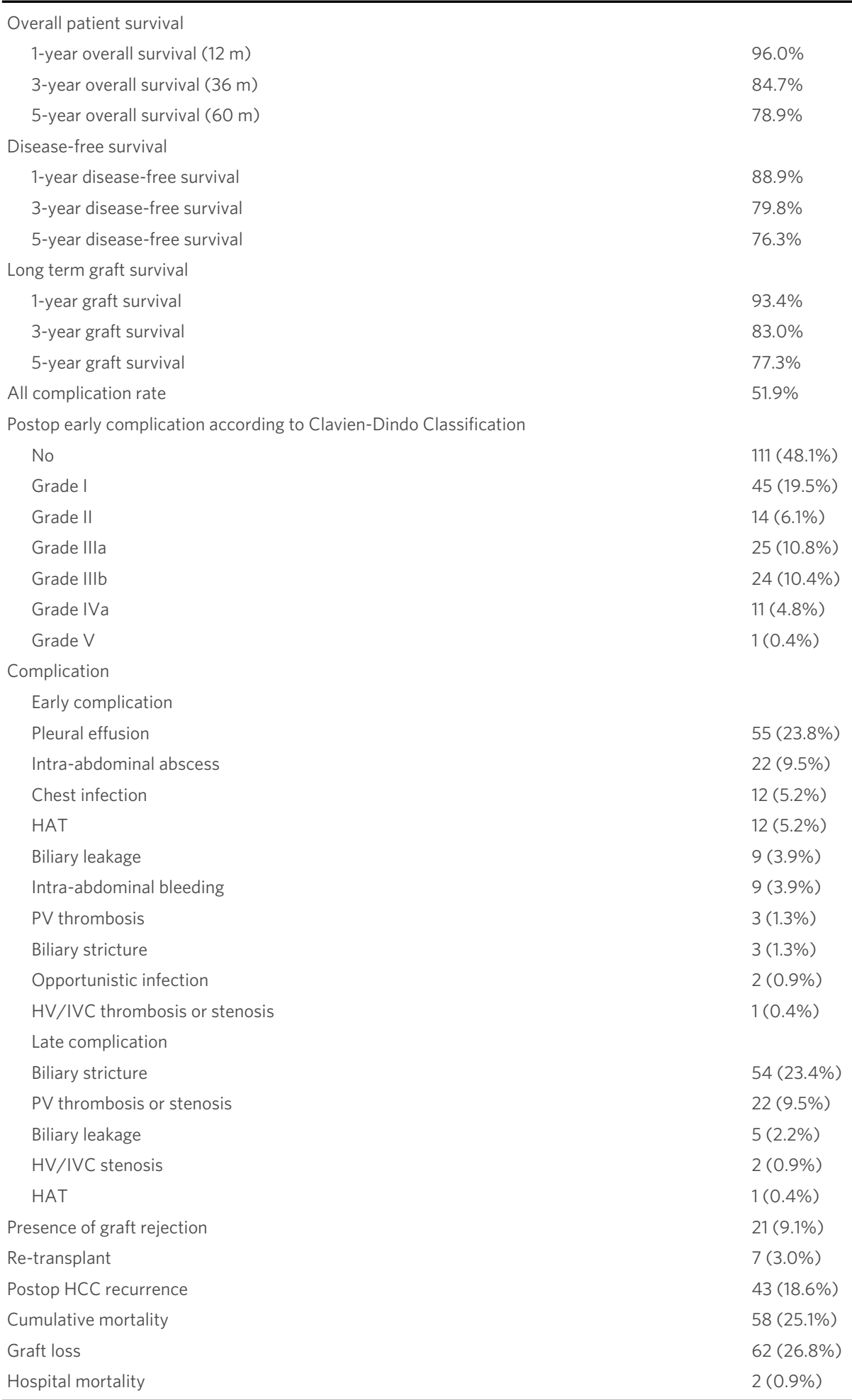

HV: Heptatic vein; IVC: inferior vena cava; PV: portal vein; HAT: hepatic artery thrombosis; HCC: hepatocellular carcinoma. 


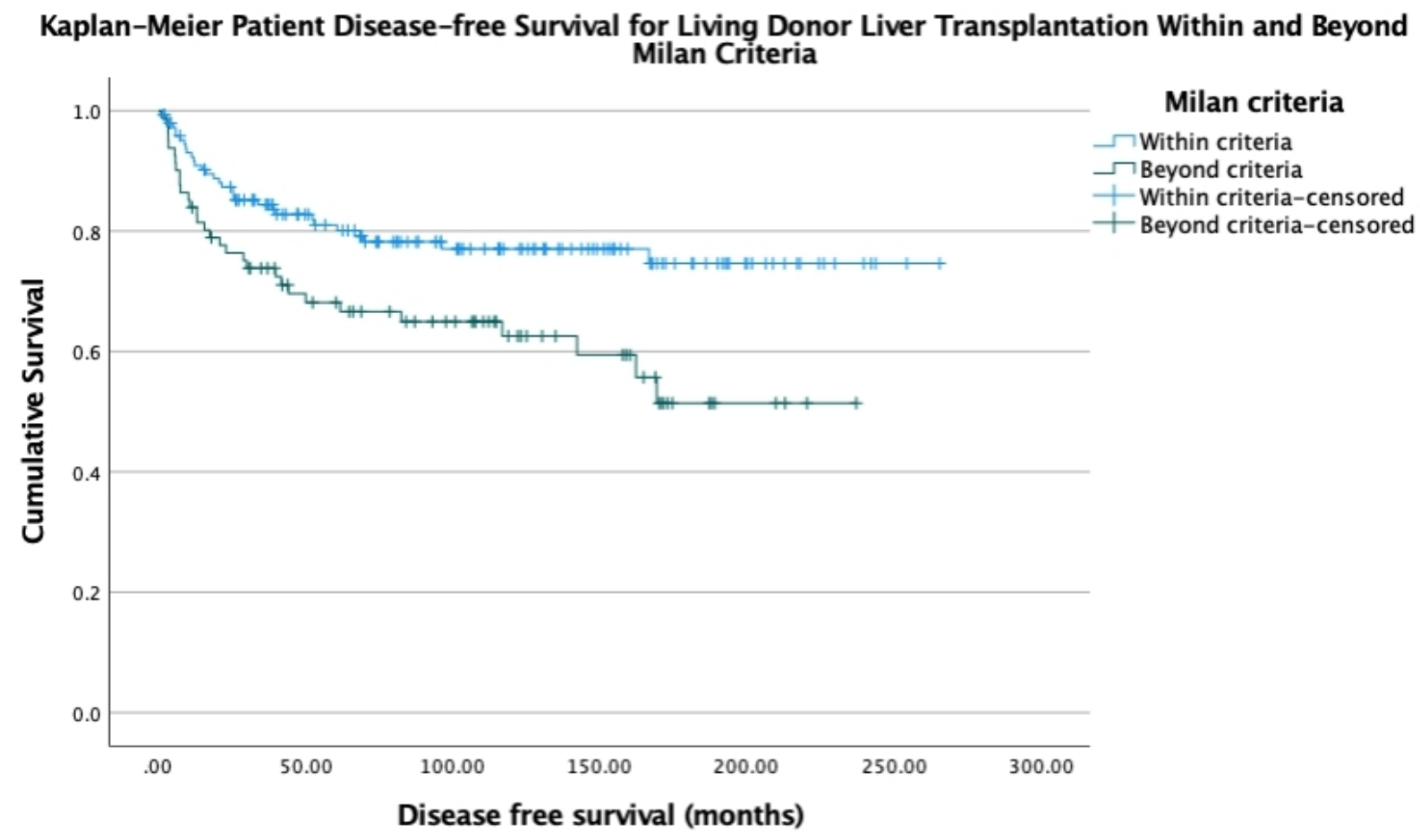

Figure 1. Kaplan-Meier patient disease-free survival after living donor liver transplantation within and beyond Milan criteria $(P=0.008)$.

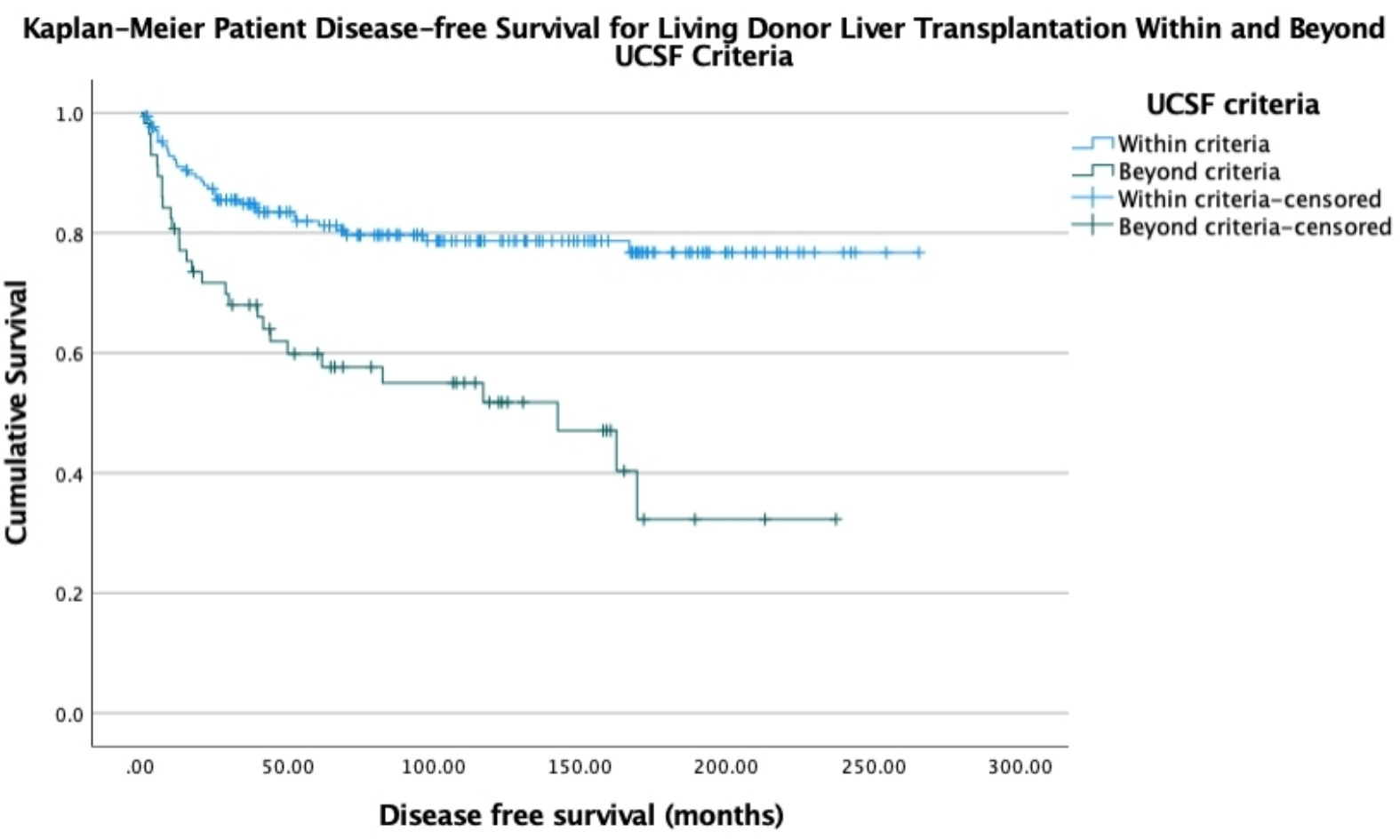

Figure 2. Kaplan-Meier patient disease-free survival after living donor liver transplantation within and beyond University of California, San Francisco (UCSF) criteria $(P<0.001)$. 


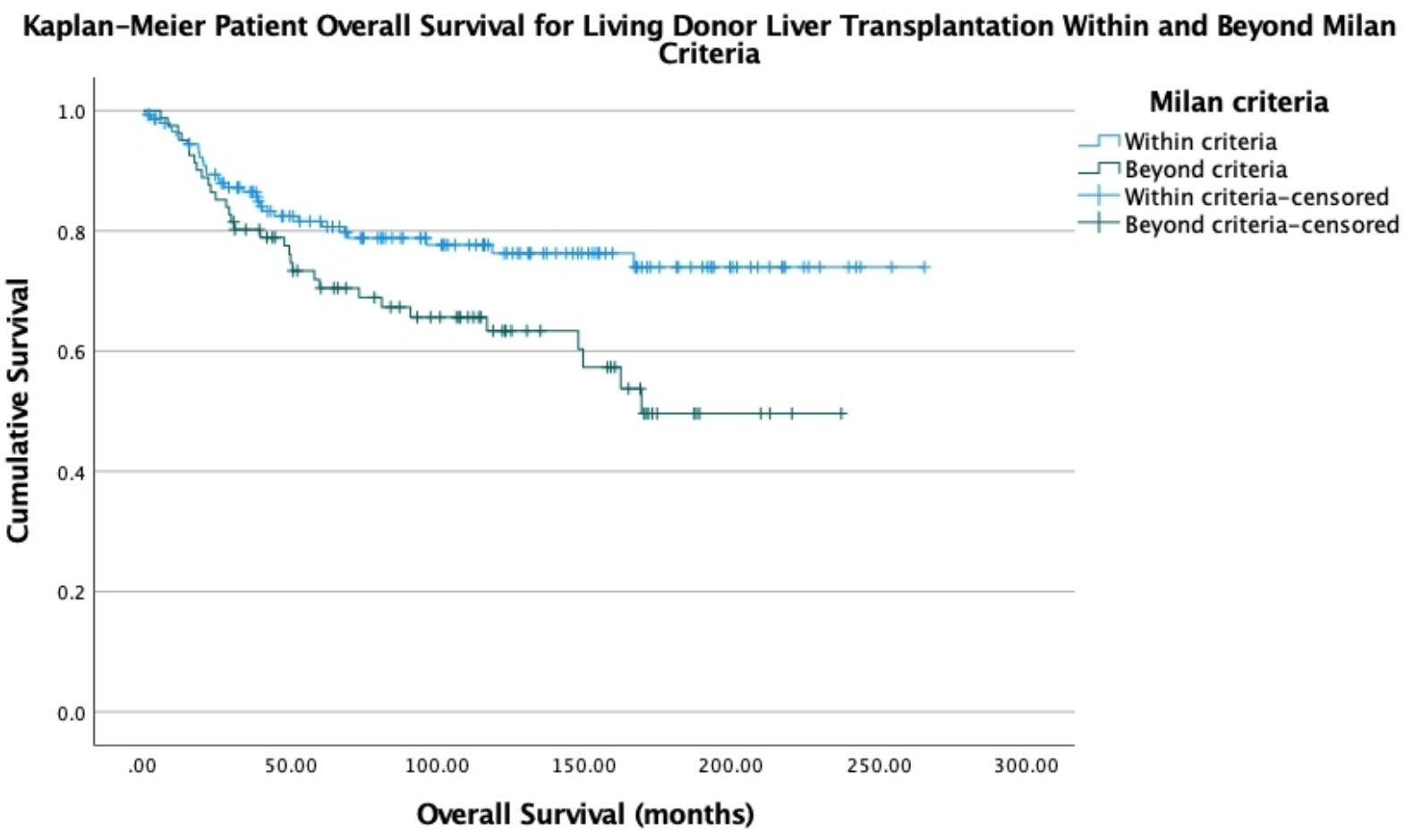

Figure 3. Kaplan-Meier patient overall survival after living donor liver transplantation within and beyond Milan criteria $(P=0.018)$.

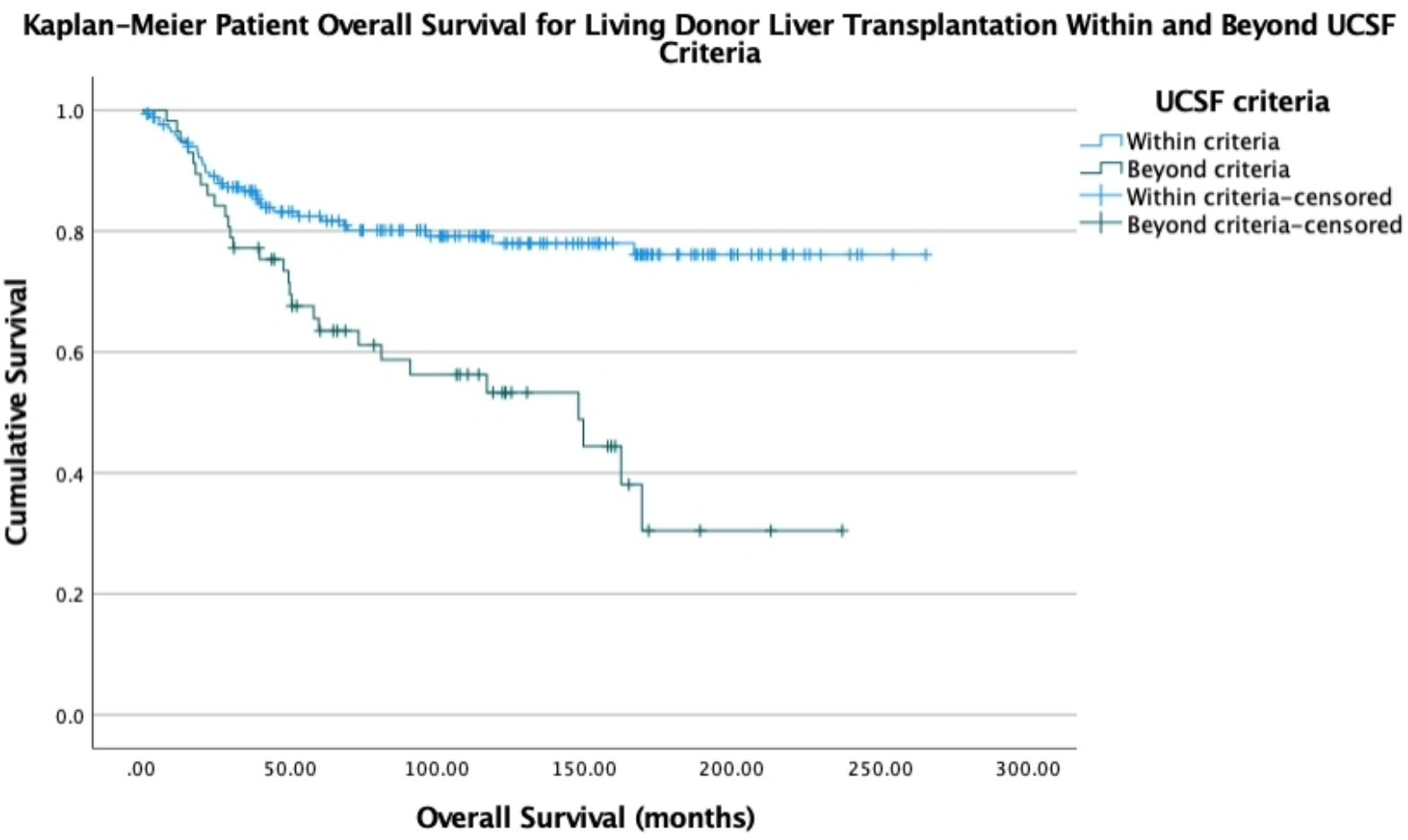

Figure 4. Kaplan-Meier patient overall survival after living donor liver transplantation within and beyond University of California, San Francisco (UCSF) criteria $(P<0.001)$.

criteria as the main selection criteria (solitary HCC $\leq 6.5 \mathrm{~cm}$, or $\leq 3$ nodules with the largest tumour $\leq$ 
$4.5 \mathrm{~cm}$, and a total diameter $\leq 8 \mathrm{~cm})^{[23,24]}$. It predicts better post-transplant survival and fewer complications ${ }^{[8]}$. The UCSF criteria act as a modest expansion on the Milan criteria that allow transplantation in $10 \%$ more HCC patients without compromising survival ${ }^{[22]}$. A multicentre study reported the 5-year survival rates of LDLT within the UCSF criteria to range between $66 \%$-90\%, with variations attributed to the transplant team experience and resource availability ${ }^{[25]}$. Selected patients with more advanced HCC underwent radionucleotide bone scan and positron emitting tomography using a C-11 acetate tracer. Patients with evidence of diffuse HCC, major vascular invasion or extrahepatic metastasis were then excluded.

Donor voluntarism provided flexibility in recipient selection. Patients slightly over the UCSF criteria were still accepted, given a favourable biological tumour profile. AFP serves as an indicator of the patients' liver function. Its role in predicting post-transplant HCC recurrence has been widely supported ${ }^{[26-28]}$. With available donors, the patients experienced shorter waiting time on the list and were prevented from further deterioration of liver function and disease progression ${ }^{[25]}$.

In terms of donor selection, donor voluntarism serves as the prerequisite before undertaking further assessments for the suitability of donors. Clinical psychologists assess donors in the absence of the recipients and other parties for their voluntarism in liver graft donation. Subsequently, donors are evaluated for ABO blood group compatibility, negative HBV and hepatitis C virus (HCV) serology, and any acute or chronic illness. Donors undergo CT to assess for adequate CT volumetry of the liver graft for the recipient and liver remnant for the donor.

The process of the recipient and donor surgery has been discussed. The use of the extended right lobe graft with the inclusion of the middle hepatic vein provided a larger liver volume and minimized the risk of developing SFSS ${ }^{[15]}$.

\section{Factors associated with HCC recurrence}

Tumour recurrence remained one of the significant factors that compromise recipients' survival ${ }^{[25]}$.

Various factors related to tumour recurrence have been identified. Todo et al. ${ }^{[29]}$ pinpointed elevated preoperative AFP level, tumour size, vascular invasion, and bilobar distribution as independent risk factors for recurrence after LDLT. Our centre's experience echoed the findings above and demonstrated significantly worse overall and disease-free survival when the Milan criteria and the UCSF criteria were not met $^{[30]}$.

There are ongoing discussions about the survival benefits of primary and salvage liver transplantation (LT). Bhangui et al. ${ }^{[31]}$ reported a higher incidence of non-transplantable recurrence and lower survival rates in the group receiving salvage LT than primary LT. Hepatic resection followed by salvage LT is performed under the local context of substantial organ shortage. While primary LT may not always be possible, this approach gives patients a possible chance of cure.

Close surveillance is essential for the timely detection of recurrence at a transplantable stage. Patients are follow-up every three months with clinical examination, measurement of AFP level, and CT scan of the abdomen and thorax. Liver biopsy is carried out in cases of suspected recurrence. 
Small for size graft and portal venous flow modulation

With donor safety being one of the most important considerations in LDLT, many centres embrace the use of left lobe graft, which reduced the risk to the donors by five times ( $0.1 \%$ with left lobe graft compared to $0.5 \%$ with right lobe graft ${ }^{[12]}$. Despite that, left lobe grafts are frequently small-for-size graft (graft-torecipient weight ratio $<0.8$, or graft volume to standard liver volume $<30 \%)^{[13,14]}$ which are associated with the development of small-for-size syndrome (SFSS) in transplant recipients. It may further aggravate into early graft failure due to insufficient liver volume for meeting the metabolic demand of a larger recipient ${ }^{[8]}$. Compared to the left lobe graft, the extended right lobe graft constitutes a higher liver volume ${ }^{[15]}$ and reduces the chance of SFSS.

The development of SFSS is subject to interrelating factors of the graft size, graft quality, portal inflow, and venous outflow ${ }^{[8]}$. A previous study suggested compromised recipient outcome with graft volume to standard liver volume $<35 \%{ }^{[16]}$, modulation of portal venous flow becomes an important technique to minimize the chance of SFSS.

The regulation of flow and portal venous pressure should always be treated with caution. Hyperperfusion, common in the use of small-for-size graft or left lobe graft in LDLT, increases sinusoidal pressure and damages liver endothelium ${ }^{[17]}$. It is demonstrated that raised portal pressure in the early postoperative phase is linked to poorer recipient survival with small-for-size grafts ${ }^{[18]}$. At our centre, portal vein flow rate is routinely measured with a flowmeter. We proposed splenic artery ligation for portal inflow > $250 \mathrm{~mL} / \mathrm{min} / 100 \mathrm{~g}$ of graft weight. The subsequent cut in flow from the splenic vein lowers portal vein pressure back to normal ${ }^{[8]}$. Portocaval shunt and mesocaval shunt are also valid in reducing portal pressure. However, potential complications associated with porto-systemic shunting remains a concern. It also adds difficulty to the second laparotomy, if needed ${ }^{[8]}$. In case of portal vein hypoperfusion after implantation, which is commonly seen in very cirrhotic patients, pre-existing porto-systemic shunts are identified and ligated to increase the portal venous flow. Effect and magnitude of portal vein flow modulation is reflected by the change in portal venous manometric assessment. With the above techniques, an overall graft and patient survival rate of $84 \%$ and $96 \%$, respectively, were achieved ${ }^{[15]}$.

\section{Post-transplant complication and surveillance}

HAT is a serious post-transplant complication associated with early graft loss and increased recipient mortality. It remained the most common arterial complication before introduction of the microvascular techniques. Compared to DDLT, the use of a hemi-graft that involves only the left or right hepatic artery in LDLT is also associated with a higher risk of $\mathrm{HAT}^{[11]}$. The application of microsurgery successfully reduced its incidence from $25 \%{ }^{[32]}$ to $1.6 \%-3.8 \%{ }^{[33-37]}$.

The highest standard of postoperative care is offered to the recipients of LDLT. The donors are administered to the intensive care unit with strict monitoring of liver function. Fluid restriction is crucial in preserving the post-LT liver function. It helps regulate central venous pressure that ensures a sufficient volume of venous return to the liver remnant. The central venous catheter and urinary catheter are removed as soon as possible to reduce the risk of infection. Breathing exercises are recommended that ensure a speedy recovery ${ }^{[1]}$. Infusion of insulin and albumin solution allows control of blood glucose level and compensates for the impairment in coagulative function. Infection is one of the common post-LT complications. Prophylactic antibiotics will be continued postoperatively. Frequent monitoring of hepatic artery blood flow using bedside doppler ultrasonography helps detect and salvage early case of HAT $^{[36]}$. Haemodialysis may be required in cases that present with transient renal function impairment. Early resumption of enteral feeding yields better patient outcomes ${ }^{[11]}$. 
Postoperative anti-viral and immunosuppressive treatment

Adequate immunosuppressive and antimicrobial treatment after LDLT reduces the chance of graft loss and HCC recurrence.

Our centre has adopted a quadruple immunosuppression regime for all transplant recipients since 2001. It involves induction with basiliximab, an interlukin-2 receptor antibody, and two perioperative injections of steroids. And for postoperative maintenance, mycophenolate mofetil and tacrolimus are given.

In the past, cyclosporin A was used as the first-line immunosuppressive therapy for post-LT recipients. The use of the more potent calcineurin inhibitor, tacrolimus, is associated with superior survival and rejection $\operatorname{rates}^{[38]}$. However, its application is limited by the concerns on the drug's nephrotoxicity and neurotoxicity ${ }^{[39]}$. More importantly, studies revealed that tacrolimus is potentially oncogenic, predisposing patients to HCC recurrence ${ }^{[40,41]}$.

In recent years, the mammalian target of rapamycin (mTOR) inhibitors is used as a calcineurin inhibitorsparing agent with anti-tumour properties ${ }^{[42]}$. Compared with tacrolimus, the application of sirolimus and everolimus minimize the risk of renal impairment ${ }^{[43]}$. A meta-analysis study demonstrated prolonged overall recipient survival and attenuated tumour recurrence with the use of mTOR inhibitor ${ }^{[44]}$. Despite concerns on the potential association of sirolimus usage and the increased risk of HAT, there is no proof of the prothrombotic effect by the drug. Two separate studies revealed a reduced incidence of HAT in the treatment group, compared to the control group using corticosteroids ${ }^{[45,46]}$. In our centre, we adopted an early use of mTOR inhibitor (i.e., 3 months after liver transplantation) together with low maintenance dose of calcineurin inhibitor in patients with high risk of HCC recurrence.

In Hong Kong, HBV-related cirrhosis is the primary cause of HCC, which accounts for a large proportion of all transplant cases. Antiviral agents are commonly applied in post-LT treatment, which reduces the chance of graft loss, viral hepatitis, and HCC recurrence ${ }^{[47,48]}$. In recent years, entecavir monotherapy has replaced lamivudine and hepatitis B immunoglobulin as the standard antiviral therapy ${ }^{[4]}$. The antiviral agent is now used at our centre, which gives an excellent long-term overall survival rate of $85 \%$. Its high degree of viral suppression also reduces HBV-related complications ${ }^{[50]}$.

\section{Future directions for LDLT}

Laparoscopic and robotic surgery

Our centre practised laparoscopic and robotic hepatectomy surgeries for selected cases. The technique is one of the areas for future advancement with expected extensive application in the practise of LDLT.

Minimally invasive surgery has been reported as a safe and effective approach in the management of liver diseases. Its application expanded since the first laparoscopic cholecystectomy published in $1992^{[51]}$. Since then, numerous reviews and meta-analyses validated the benefits of laparoscopic procedures, such as reduced blood loss, shorter hospital stay, fewer postoperative complications, and a similar oncological outcome as in open surgery ${ }^{[51-58]}$. Many experienced centres now adopt the adult-to-child laparoscopic living donor left lateral sectionectomy ${ }^{[59]}$. Application of the living donor right hepatectomy remains restricted due to safety concerns in minimally invasive donor hepatectomy ${ }^{[60]}$.

Kim et al. ${ }^{[61]}$ 's report emphasized strict selection criteria based on vascular and biliary structure. Donors with single and more extended right hepatic artery, portal vein, hepatic duct, and favourable hepatic vein anatomy were selected, excluding graft of over 700 g. Laparoscopic hepatectomy still follows surgical 
techniques ${ }^{[62]}$ in open surgery, including use of the Cavitron ultrasonic surgical aspirator, hanging manoeuvre, and Pringle's manoeuvre ${ }^{[63,64]}$. Complete liver mobilization before resection allows better manipulation of the transaction plane. Intraoperative indocyanine green cholangiography guides precise bile duct division and improves patient safety ${ }^{[65]}$.

Robotic-assisted (RA) approaches in liver resection are documented as safe and feasible. Better visualization of the surgical field and improved range of motion are now possible under the robotic system ${ }^{[6]}$. With the rubber band retraction technique and the Da Vinci Fluorescence imaging vision system, RA provides a clear segmental boundary of the liver parenchyma. It allows a more careful dissection of the hepatic hilum and inferior vena cava ${ }^{[67-69]}$. In donor hepatectomy, the robotic system closes the hepatic duct stump with a running suture, reducing the risk of donor biliary strictures, especially when shorter bile ducts are used ${ }^{[70]}$.

Series reports by Chen et al. ${ }^{[2]}$ quoted comparable short-term outcomes, vascular complications, and biliary complications in RA, compared to open surgery. Studies indicated a similar intraoperative blood loss and warm ischaemic time with reduction in analgesia, and shorter return to work ${ }^{[7] 1}$. However, one should note the protracted learning curve in laparoscopic and robotic hepatectomy. Accumulation of experience is crucial in the success in RA liver transplantation ${ }^{[2,73]}$.

\section{Tumour markers}

Tumour markers provide a supplementary evaluation of the disease outcome and recurrence. Specific markers, such as AFP, have been added to the patient selection criteria for LDLT at many centres ${ }^{[21,74]}$. Its effectiveness in the prediction of tumour aggressiveness and post-transplant tumour recurrence has been validated. Protein induced by vitamin K absence-II (PIVKA-II) is a biomarker developed for the diagnosis of HCC. The marker itself promotes cellular proliferation and migration, as well as induces the expression of angiogenetic factors. It is, therefore, predictive of the tumour aggressiveness and post-LT outcome ${ }^{[75,76]}$. Studies claimed that PIVKA-II has the potential to detect HCC early with improved sensitivity and specificity ${ }^{[77,78]}$. Some centres support the combination of AFP and PIVKA-II in predicting tumour recurrence ${ }^{[79]}$.

AFP mRNA aims to predict post-LT recurrence by detecting residual cancer cells in the circulating blood $^{[80]}$. AFP-L3\% is a fucosylated form of AFP, predicting HCC recurrence and prognosis following local ablation and hepatectomy ${ }^{[8]}$. The process of tumour necrosis and angiogenesis release systemic inflammatory markers. Neutrophil-to-lymphocyte ratio is applied in patient selection for DDLT and LDLT in adjunct to the model for end-stage liver disease (MELD) score and the Milan criteria ${ }^{[82]}$. An increased level of neutrophil-to-lymphocyte ratio $(>5)$ predicts lower recurrence-free survival and overall survival in individual HCC patients ${ }^{[83]}$.

Many centres now propose a combined use of morphological criteria and tumour markers ${ }^{[27,74,84]}$. With evolving evidence on the predictive power of individual biomarkers, it seems rational to combine the prognostic ability of different markers for a more accurate prediction of the transplant outcome. For example, the BALAD staging score, developed by Toyoda et al.$^{[85]}$, uses a combination of AFP (> $400 \mathrm{ng} / \mathrm{mL})$, AFP-L3 (> 15\%), and DCP (> $100 \mathrm{mAU} / \mathrm{mL})$, which showed reduced survival per level of increment in the markers $(P<0.0001)$.

LDLT is an ideal treatment for HCC in Hong Kong with regard to the critical organ shortage and high demand for transplantation. Our centre practises careful selection for HCC patients using the UCSF criteria, supplemented by AFP level and the MELD score. Slight flexibility is offered to enthusiastic donors and 
recipients in LDLT while balancing the risks and benefits. We pioneered in using the extended right lobe graft and the novel hepatic venoplasty technique, which lessen the risk of hyperperfusion and SFSS with improved overall recipient survival. A 5-year overall and disease-free survival rate of $78.9 \%$ and $76.3 \%$, respectively, were achieved.

\section{DECLARATIONS}

\section{Authors' contributions}

Contributed to study design, manuscript writing, and data analysis: Mok JHM, Ma KW

Supervised the research project: Chok KSH

\section{Availability of data and materials}

Not applicable.

\section{Financial support and sponsorship}

None.

\section{Conflicts of interest}

All authors declared that there are no conflicts of interest.

\section{Ethical approval and consent to participate}

Not applicable.

\section{Consent for publication}

Not applicable.

\section{Copyright}

(c) The Author(s) 2022.

\section{REFERENCES}

1. Yoshizumi T, Harimoto N, Itoh S, et al. Living donor liver transplantation for hepatocellular carcinoma within milan criteria in the present era. Anticancer Res 2016;36:439-45. PubMed

2. Chen CL, Kabiling CS, Concejero AM. Why does living donor liver transplantation flourish in Asia? Nat Rev Gastroenterol Hepatol 2013;10:746-51. DOI PubMed

3. Worldwide liver transplant from deceased donors 2019 (PMP). Available from: https://www.irodat.org/?p=database [Last accessed on 7 Jan 2022]. DOI

4. Lo CM, Fan ST, Liu CL, et al. Adult-to-adult living donor liver transplantation using extended right lobe grafts. Ann Surg 1997;226:261-9; discussion 269-70. DOI PubMed PMC

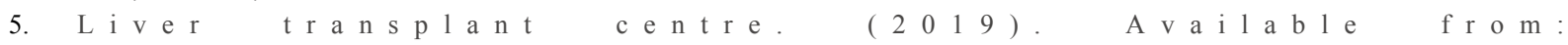
https://www8.ha.org.hk/qmh/patient_and_visitor/medical_services/liver_transplant_centre.aspx [Last accessed on 7 Jan 2022]. DOI

6. Blok JJ, de Boer JD, Putter H, et al; Eurotransplant Liver Intestine Advisory Committee. The center effect in liver transplantation in the Eurotransplant region: a retrospective database analysis. Transpl Int 2018;31:610-9. DOI PubMed

7. Macomber CW, Shaw JJ, Santry H, et al. Centre volume and resource consumption in liver transplantation. HPB (Oxford) 2012;14:554-9. DOI PubMed PMC

8. Chan SC, Lo CM, Ng KK, Ng IO, Yong BH, Fan ST. Portal inflow and pressure changes in right liver living donor liver transplantation including the middle hepatic vein. Liver Transpl 2011;17:115-21. DOI PubMed

9. Fan ST, Lo CM, Liu CL. Technical refinement in adult-to-adult living donor liver transplantation using right lobe graft. Ann Surg 2000;231:126-31. DOI PubMed PMC

10. Lo CM, Fan ST, Liu CL, Wong J. Hepatic venoplasty in living-donor liver transplantation using right lobe graft with middle hepatic vein. Transplantation 2003;75:358-60. DOI PubMed

11. Fan ST, Wei WI, Yong BH, et al. Living donor liver transplantation. World Scientific; 2011.

12. She WH, Chok KS, Fung JY, Chan AC, Lo CM. Outcomes of right-lobe and left-lobe living-donor liver transplantations using smallfor-size grafts. World J Gastroenterol 2017;23:4270-7. DOI PubMed PMC

13. Lo CM, Fan ST, Liu CL, et al. Minimum graft size for successful living donor liver transplantation. Transplantation 1999;68:1112-6. DOI PubMed 
14. Kawasaki S, Makuuchi M, Matsunami H, et al. Living related liver transplantation in adults. Ann Surg 1998;227:269-74. DOI PubMed PMC

15. de Villa VH, Chen CL, Chen YS, et al. Right lobe living donor liver transplantation-addressing the middle hepatic vein controversy. Ann Surg 2003;238:275-82. DOI PubMed PMC

16. Ma KW, Wong KHC, Chan ACY, et al. Impact of small-for-size liver grafts on medium-term and long-term graft survival in living donor liver transplantation: a meta-analysis. World J Gastroenterol 2019;25:5559-68. DOI PubMed PMC

17. Man K, Fan ST, Lo CM, et al. Graft injury in relation to graft size in right lobe live donor liver transplantation: a study of hepatic sinusoidal injury in correlation with portal hemodynamics and intragraft gene expression. Ann Surg 2003;237:256-64. DOI PubMed PMC

18. Ito T, Kiuchi T, Yamamoto H, et al. Changes in portal venous pressure in the early phase after living donor liver transplantation: pathogenesis and clinical implications. Transplantation 2003;75:1313-7. DOI PubMed

19. Wei WI, Lam LK, Ng RW, et al. Microvascular reconstruction of the hepatic artery in live donor liver transplantation: experience across a decade. Arch Surg 2004;139:304-7. DOI PubMed

20. Dindo D, Demartines N, Clavien PA. Classification of surgical complications: a new proposal with evaluation in a cohort of 6336 patients and results of a survey. Ann Surg 2004;240:205-13. DOI PubMed PMC

21. Arbuthnot P, Kew M. Hepatitis B virus and hepatocellular carcinoma. Int J Exp Pathol 2001;82:77-100. DOI PubMed PMC

22. Mazzaferro V, Regalia E, Doci R, et al. Liver transplantation for the treatment of small hepatocellular carcinomas in patients with cirrhosis. N Engl J Med 1996;334:693-9. DOI PubMed

23. Yao FY, Ferrell L, Bass NM, et al. Liver transplantation for hepatocellular carcinoma: expansion of the tumor size limits does not adversely impact survival. Hepatology 2001;33:1394-403. DOI

24. Ma KW, Chok KSH, Fung JYY, Lo CM. Liver transplantation for hepatitis B virus-related hepatocellular carcinoma in Hong Kong. $J$ Clin Transl Hepatol 2018;6:283-8. DOI PubMed PMC

25. Lin C, Elsarawy AMAA, Chen C. Living donor liver transplantation for hepatocellular carcinoma. In: Abdeldayem HM, editor. Updates in Liver Cancer. InTech; 2017. DOI

26. Mailey B, Artinyan A, Khalili J, et al. Evaluation of absolute serum $\alpha$-fetoprotein levels in liver transplant for hepatocellular cancer. Arch Surg 2011;146:26-33. DOI PubMed

27. Todo S, Furukawa H, Tada M. Extending indication: role of living donor liver transplantation for hepatocellular carcinoma. Liver Transpl 2007;13:S48-S54. DOI PubMed

28. Zheng SS, Xu X, Wu J, et al. Liver transplantation for hepatocellular carcinoma: Hangzhou experiences. Transplantation 2008;85:1726-32. DOI

29. Todo S, Furukawa H; Japanese Study Group on Organ Transplantation. Living donor liver transplantation for adult patients with hepatocellular carcinoma: experience in Japan. Ann Surg 2004;240:451-9; discussion 459-61. DOI PubMed PMC

30. Ng KK, Lo CM, Chan SC, Chok KS, Cheung TT, Fan ST. Liver transplantation for hepatocellular carcinoma: the Hong Kong experience. J Hepatobiliary Pancreat Sci 2010;17:548-54. DOI PubMed

31. Bhangui P, Allard MA, Vibert E, et al. Salvage versus primary liver transplantation for early hepatocellular carcinoma: do both strategies yield similar outcomes? Ann Surg 2016;264:155-63. DOI PubMed

32. Broelsch CE, Whitington PF, Emond JC, et al. Liver transplantation in children from living related donors. Surgical techniques and results. Ann Surg 1991;214:428-37; discussion 437-9. DOI PubMed PMC

33. Hatano E, Terajima H, Yabe S, et al. Hepatic artery thrombosis in living related liver transplantation. Transplantation 1997;64:1443-6. DOI PubMed

34. Sakamoto Y, Harihara Y, Nakatsuka T, et al. Rescue of liver grafts from hepatic artery occlusion in living-related liver transplantation. Br J Surg 1999;86:886-9. DOI PubMed

35. Goldstein MJ, Salame E, Kapur S, et al. Analysis of failure in living donor liver transplantation: differential outcomes in children and adults. World J Surg 2003;27:356-64. DOI PubMed

36. Millis JM, Cronin DC, Brady LM, et al. Primary living-donor liver transplantation at the University of Chicago: technical aspects of the first 104 recipients. Ann Surg 2000;232:104-11. DOI PubMed PMC

37. Uchiyama H, Hashimoto K, Hiroshige S, et al. Hepatic artery reconstruction in living-donor liver transplantation: a review of its techniques and complications. Surgery 2002;131:S200-4. DOI PubMed

38. McAlister VC, Haddad E, Renouf E, Malthaner RA, Kjaer MS, Gluud LL. Cyclosporin versus tacrolimus as primary immunosuppressant after liver transplantation: a meta-analysis. Am J Transplant 2006;6:1578-85. DOI PubMed

39. Randhawa PS, Starzl TE, Demetris AJ. Tacrolimus (FK506)-associated renal pathology. Adv Anat Pathol 1997;4:265-76. DOI PubMed PMC

40. Vivarelli M, Cucchetti A, Piscaglia F, et al. Analysis of risk factors for tumor recurrence after liver transplantation for hepatocellular carcinoma: key role of immunosuppression. Liver Transpl 2005;11:497-503. DOI PubMed

41. Hojo M, Morimoto T, Maluccio M, et al. Cyclosporine induces cancer progression by a cell-autonomous mechanism. Nature 1999;397:530-4. DOI PubMed

42. Guba M, von Breitenbuch P, Steinbauer M, et al. Rapamycin inhibits primary and metastatic tumor growth by antiangiogenesis: involvement of vascular endothelial growth factor. Nat Med 2002;8:128-35. DOI PubMed

43. Diekmann F, Campistol JM. Practical considerations for the use of mTOR inhibitors. Transplant Res 2015;4:5. DOI PubMed PMC

44. Liang W, Wang D, Ling X, et al. Sirolimus-based immunosuppression in liver transplantation for hepatocellular carcinoma: a metaanalysis. Liver Transpl 2012;18:62-9. DOI PubMed 
45. Trotter J. Sirolimus in liver transplantation. Transplant Proc 2003;35:S193-200. DOI PubMed

46. McAlister VC, Peltekian KM, Malatjalian DA, et al. Orthotopic liver transplantation using low-dose tacrolimus and sirolimus. Liver Transpl 2001;7:701-8. DOI PubMed

47. Fung J. Management of chronic hepatitis B before and after liver transplantation. World J Hepatol 2015;7:1421-6. DOI PubMed PMC

48. Lo CM, Cheung ST, Lai CL, et al. Liver transplantation in Asian patients with chronic hepatitis B using lamivudine prophylaxis. Ann Surg 2001;233:276-81. DOI PubMed PMC

49. Fung J, Chan SC, Cheung C, et al. Oral nucleoside/nucleotide analogs without hepatitis B immune globulin after liver transplantation for hepatitis B. Am J Gastroenterol 2013;108:942-8. DOI PubMed

50. Fung J, Wong T, Chok K, et al. Long-term outcomes of entecavir monotherapy for chronic hepatitis B after liver transplantation: results up to 8 years. Hepatology 2017;66:1036-44. DOI PubMed

51. Jr W. The first laparoscopic cholecystectomy. JSLS 2001;5:89-94. DOI

52. Nguyen KT, Marsh JW, Tsung A, Steel JJ, Gamblin TC, Geller DA. Comparative benefits of laparoscopic vs open hepatic resection: a critical appraisal. Arch Surg 2011;146:348-56. DOI PubMed

53. Simillis C, Constantinides VA, Tekkis PP, Darzi A, Lovegrove R, Jiao L, Antoniou A. Laparoscopic versus open hepatic resections for benign and malignant neoplasms-a meta-analysis. Surgery 2007;141:203-11. DOI PubMed

54. Croome KP, Yamashita MH. Laparoscopic vs open hepatic resection for benign and malignant tumors: an updated meta-analysis. Arch Surg 2010;145:1109-18. DOI PubMed

55. Zhou YM, Shao WY, Zhao YF, Xu DH, Li B. Meta-analysis of laparoscopic versus open resection for hepatocellular carcinoma. Dig Dis Sci 2011;56:1937-43. DOI PubMed

56. Mirnezami R, Mirnezami AH, Chandrakumaran K, et al. Short- and long-term outcomes after laparoscopic and open hepatic resection: systematic review and meta-analysis. HPB (Oxford) 2011;13:295-308. DOI PubMed PMC

57. Mizuguchi T, Kawamoto M, Meguro M, et al. Laparoscopic hepatectomy: a systematic review, meta-analysis, and power analysis. Surg Today 2011;41:39-47. DOI PubMed

58. Li N, Wu YR, Wu B, Lu MQ. Surgical and oncologic outcomes following laparoscopic versus open liver resection for hepatocellular carcinoma: a meta-analysis. Hepatol Res 2012;42:51-9. DOI PubMed

59. Kim KH, Jung DH, Park KM, et al. Comparison of open and laparoscopic live donor left lateral sectionectomy. Br J Surg 2011;98:1302-8. DOI PubMed

60. Kim SH, Lee SD, Kim YK, Park SJ. Pushing the frontiers of living donor right hepatectomy. World J Gastroenterol 2014;20:18061-9. DOI PubMed PMC

61. Kim KH, Kang SH, Jung DH, et al. Initial outcomes of pure laparoscopic living donor right hepatectomy in an experienced adult living donor liver transplant center. Transplantation 2017;101:1106-10. DOI PubMed

62. Wakabayashi G, Nitta H, Takahara T, Shimazu M, Kitajima M, Sasaki A. Standardization of basic skills for laparoscopic liver surgery towards laparoscopic donor hepatectomy. J Hepatobiliary Pancreat Surg 2009;16:439-44. DOI PubMed

63. Kim JH, Ryu DH, Jang LC, Choi JW. Lateral approach liver hanging maneuver in laparoscopic anatomical liver resections. Surg Endosc 2016;30:3611-7. DOI PubMed

64. Pringle JH. V. Notes on the arrest of hepatic hemorrhage due to trauma. Ann Surg 1908;48:541-9. DOI PubMed PMC

65. Ishizawa T, Saiura A, Kokudo N. Clinical application of indocyanine green-fluorescence imaging during hepatectomy. Hepatobiliary Surg Nutr 2016;5:322-8. DOI PubMed PMC

66. Giulianotti PC, Coratti A, Angelini M, et al. Robotics in general surgery: personal experience in a large community hospital. Arch Surg 2003;138:777-84. DOI PubMed

67. Choi GH, Choi SH, Kim SH, et al. Robotic liver resection: technique and results of 30 consecutive procedures. Surg Endosc 2012;26:2247-58. DOI PubMed

68. Choi SH, Choi GH, Han DH, Choi JS. Laparoscopic liver resection using a rubber band retraction technique: usefulness and perioperative outcome in 100 consecutive cases. Surg Endosc 2015;29:387-97. DOI PubMed

69. Park JI, Kim KH, Kim HJ, et al. Highlights of the third expert forum of Asia-pacific laparoscopic hepatectomy; endoscopic and laparoscopic surgeons of Asia (ELSA) visionary summit 2017. Ann Hepatobiliary Pancreat Surg 2018;22:1-10. DOI PubMed PMC

70. Chen PD, Wu CY, Wu YM. Use of robotics in liver donor right hepatectomy. Hepatobiliary Surg Nutr 2017;6:292-6. DOI PubMed PMC

71. Chen PD, Wu CY, Hu RH, et al. Robotic liver donor right hepatectomy: a pure, minimally invasive approach. Liver Transpl 2016;22:1509-18. DOI PubMed

72. Zhu P, Liao W, Ding zy, et al. learning curve in robot-assisted laparoscopic liver resection. J Gastrointest Surg 2019;23:1778-87. DOI PubMed

73. Saito Y, Yamada S, Imura S, et al. A learning curve for laparoscopic liver resection: an effective training system and standardization of technique. Transl Gastroenterol Hepatol 2018;3:45. DOI PubMed PMC

74. Sapisochin G, Goldaracena N, Laurence JM, et al. The extended Toronto criteria for liver transplantation in patients with hepatocellular carcinoma: a prospective validation study. Hepatology 2016;64:2077-88. DOI PubMed

75. Suzuki M, Shiraha H, Fujikawa T, et al. Des-gamma-carboxy prothrombin is a potential autologous growth factor for hepatocellular carcinoma. J Biol Chem 2005;280:6409-15. DOI PubMed

76. Fujikawa T, Shiraha H, Ueda N, et al. Des-gamma-carboxyl prothrombin-promoted vascular endothelial cell proliferation and migration. J Biol Chem 2007;282:8741-8. DOI PubMed 
77. Tanaka Y, Kashiwagi T, Tsutsumi H, et al. Sensitive measurement of serum abnormal prothrombin (PIVKA-II) as a marker of hepatocellular carcinoma. Hepatogastroenterology 1999;46:2464-8. PubMed

78. Ikoma J, Kaito M, Ishihara T, et al. Early diagnosis of hepatocellular carcinoma using a sensitive assay for serum des-gamma-carboxy prothrombin: a prospective study. Hepatogastroenterology 2002;49:235-8. PubMed

79. Chaiteerakij R, Zhang X, Addissie BD, et al. Combinations of biomarkers and Milan criteria for predicting hepatocellular carcinoma recurrence after liver transplantation. Liver Transpl 2015;21:599-606. DOI PubMed PMC

80. Funaki NO, Tanaka J, Seto SI, Kasamatsu T, Kaido T, Imamura M. Hematogenous spreading of hepatocellular carcinoma cells: possible participation in recurrence in the liver. Hepatology 1997;25:564-8. DOI PubMed

81. Kobayashi M, Hosaka T, Ikeda K, et al. Highly sensitive AFP-L3\% assay is useful for predicting recurrence of hepatocellular carcinoma after curative treatment pre- and postoperatively. Hepatol Res 2011;41:1036-45. DOI PubMed

82. Limaye AR, Clark V, Soldevila-Pico C, et al. Neutrophil-lymphocyte ratio predicts overall and recurrence-free survival after liver transplantation for hepatocellular carcinoma. Hepatol Res 2013;43:757-64. DOI PubMed PMC

83. Halazun KJ, Hardy MA, Rana AA, et al. Negative impact of neutrophil-lymphocyte ratio on outcome after liver transplantation for hepatocellular carcinoma. Ann Surg 2009;250:141-51. DOI PubMed

84. Ito T, Takada Y, Ueda M, et al. Expansion of selection criteria for patients with hepatocellular carcinoma in living donor liver transplantation. Liver Transpl 2007;13:1637-44. DOI PubMed

85. Toyoda H, Kumada T, Osaki Y, et al. Staging hepatocellular carcinoma by a novel scoring system (BALAD score) based on serum markers. Clin Gastroenterol Hepatol 2006;4:1528-36. DOI PubMed 